IRVINE, L. G., SIMSON, F. W., and STRACHAN, A. S. (1930), Proc. Intern. Conf. on Silicosis in Fohannesburg, I.L.O. Studies and Reports, Series F. (Industrial Hygiene), No. 13, p. 259.

JONES, W. R. (1933), $₹$. of Hyg., 33, 307.

KETTLE, E. H. (1932), F. Path. and Bact., 35, 395.

KETTLE, E. H. (1934), Ibid., 38, 201.

KING, E. J. (1945), M.R.C. Special Report Series, No. 250, p. 73. KING, E. J. (1947), Occ. Med., $4,26$.

KING, E. J., WRIGHT, B. M., and RAY, S. C. (1949), Paper read to the Path. Soc., Great Britain, January, 1949.

MCLAUGHLIN, A. I. G., ROGERS, E., and DUNHAM, K. C. (1949), Brit. $\mathcal{F}$. Ind. Med., 6, 184 .

MINERS' PHTHISIS MEDICAL BUREAU OF SOUTH AFRICA (1946), Report for the Three Years ending fuly $3 \mathrm{I}$, 1944 (South African Government Printer).
NEW YORK STATE DEPARTMENT OF LABOUR (1949) Monthly Review, 28, No. 4, April.

PERRY, K. M. A. (1948), Proc. Ninth Intern. Cong. of Ind. Med? London (in the press).

POLICARD, A. (1947), Proc. Conf. of the Institution of Minin? Engineers and Institution of Mining and Metallurgy, London p. 24 .

ROGERS, E. (1944), Paper read to the British Tuberculosis Associa tion.

SHAVER, C. G. (1948), Radiology, 50, 760.

SHAVER, C. G., and RIDDELL, A. R. (1947), f. Ind. Hyg. and Tox., 29, 145 .

VORWALD, A. J., and CARR, J. W. (1938), Amer. F. Path., 14, 4

\title{
PNEUMOCONIOSIS IN COAL MINERS
}

\author{
By J. C. McVittie, M.B., Сн.B., D.P.H. \\ Senior Medical Officer, Pneumoconiosis Medical Panel, Swansea
}

In his contribution Dr. Meiklejohn has traced historically the recognition of a relationship between disease and dusty occupation, and has shown that the ancients were aware of the industrial risk and that they, in fact, attributed the damage in some degree to the dust they inhaled. Until 1831 English medical literature had been destitute of a single treatise on diseases of trades and professions. In that year Gregory described the postmortem findings in a case of pneumoconiosis 'with black infiltration of the whole lungs' in a Scottish coal miner. Subsequently there appeared a number of references to pulmonary disease in coal miners, and valuable and critical surveys of the literature appear in an excellent paper on ' Coal Miner's Lung' by Lyle Cummins and Sladden, in the first report (medical studies) dealing with chronic pulmonary disease in South Wales coal miners published by the Medical Research Council in 1942, and in the scholarly and comprehensive study of the disease by Fletcher. Although the reference to coal miners' pneumoconiosis had priority in our literature, the later studies were concerned chiefly with miners' phthisis in metalliferous mines and with silicosis in other industries, and there was considerable delay in bringing workers in the industries within the scope of the Workmen's Compensation Act. In 1907 the Committee on Compensation for Industrial Diseases recommended that the question of scheduling silicosis (fibrosis due to the inhalation of free silica) should be kept in abeyance for the time being. Later, owing to successful measures adopted in the gold mining industry in South Africa under successive Miners' Phthisis Acts, pressure was brought to bear on the Home Office to deal with the subject. Pressure was brought not only by medical men but by workers and their representatives who wereg concerned about the incidence of the disease, and who were alert to the fact that increasing sickness and disability were associated with changing cono ditions underground. In 1925 Grenfell presentedP the evidence he had collected in South Wales. on $_{0}$ one year 22 cases (including 12 deaths) in drillers and 'hardheaders' had been collected from five collieries. It was emphasized that in one per ticular pit the disabled men, whose ages ranged from 22 to 45 years, worked in the same place 90 ro heading. Four of the group had died and pogtte mortem evidence was available. In the follo ing year Tattersall reported the tragic story of a group of rock drillers in another area. As a resulę of these and other representations a method wasy devised of dealing with the difficulties of theD situation in this country by a system of ' schemes $\stackrel{\Omega}{\Rightarrow}$ each applicable to a particular industry or groupg of industries. Thus the Various Industries, (Silicosis) Scheme, r928, applied to all workmen employed at any time on or after January I, 1929 in 'the drilling and blasting in silica rock in or incidental to the mining or quarrying of othe minerals,' and by it silica rock was defined as. containing not less than $5^{\circ}$ per cent. free silica This scheme identified the disease with particulare occupations and with particular working places, 0 and the drillers, brushers and hardheaders were required to prove the analysis of rock. Theres was, too, a strange inconsistency between the above scheme and the Refractories Industrieso (Silicosis) Scheme which came into force in 1919N The latter embraced compensation for partia incapacity as well as death and total incapacity Certification under the 1928 scheme was by a certifying surgeon who was not required to makean X-ray examination. These anomalies wer@ 
quickly remedied, and since 193 I certification of coal miners under the Silicosis and Pneumoconiosis Schemes has been by medical boards who direct an X-ray examination in every case investigated. This paper is based on the writer's experience as a member of the former Medical Board for Silicosis and later as a member of a Pneumoconiosis Medical Panel of the Ministry of National Insurance in South Wales, and on experience in the South Wales coalfields (193 I-33), in Lancashire, Northumberland, Durham and Scotland (1933-43) and again in South Wales (1943-49), and deals mainly with clinical aspects.

Within a very short time it was obvious that on the medical side silicosis in South Wales miners presented certain common features, namely gross lesions of the lungs associated with varying degrees of disability. The cases were unusual in that they did not conform to one's experience of the disease as seen in other industries because of (a) the extreme youth of the patient, (b) the comparatively short exposure in underground work, (c) the gross nature of the lesion radiographically and the infrequency of classical ' snowstorm' opacities in the lung and (d) the abnormally high incidence in certain mines. There were more applications and cases certified in the anthracite valleys, but they were not confined to that area. The writer collected and analysed all the cases seen in $193 \mathrm{I}-32$ and found that the age incidence and exposure in the attributable risk was the same in the anthracite, steam and bituminous areas. Silicosis was a disease of the young driller or ' hardheader' and of the middle-aged collier. Moreover the disease was found in workers not actually engaged in cutting, e.g. hauliers, etc. There appeared to be some other factor at work in that, even in high incidence mines, certain colliers worked with impunity throughout their working lives. Open tuberculosis was infrequently a complication of the massive type of lesion. The pathological findings suggested that the fibroid lesions were comparable, if not indistinguishable, from the infective silicosis described by the South African workers.

Experience in Lancashire and the Scottish coalfields confirmed these general features of coal miners' silicosis. Although the numbers were small, several pits seemed to cause more disease than all the other pits in the area. By the end of r933 the number of cases certified in some of the principal coalfields was as follows: South Wales and South Western, 500; Staffordshire, I7; North Wales, 2; Scotland, 5; Lancashire and Cheshire, 7; Northumberland, $\mathrm{r}$; and Durham, nil. The mine owners were by now contending that the disease was not silicosis but pneumoconiosis, and at a meeting of the medical board in 1934, Keating reported that he had collected a series of 59 cases (in South Wales) in which the board had diagnosed the disease and issued the appropriate certificates. These cases later came before the Courts which ruled that the claimants were not within the scheme, and so their claims for compensation were rejected. The records and skiagrams in this series were afterwards examined by Professor Haldane, who accepted as silicosis those where work on hardheadings was recorded and classed as pneumoconiosis those without record of such work. The most notorious highincidence mine contained only one seam of silica rock which at its thickest part was only $\frac{1}{4}$ in. thick. No drifting or heading work had been done in it for years. There was no mechanical drilling and the miners did their own ripping in top and bottom shale. The lung disease found in the miners in this and similar mines was attributed by Haldane to bronchitis and bronchiectasis, while Jones suggested that it was due to inhalation of sericite, a hydrous silicate of aluminium and potassium. On looking at the problem as a whole, it seemed impossible from the medical point of view to draw any practical distinction between silicosis ando pneumoconiosis for clinically, radiographically an $\bar{\Phi}$ pathologically they were identical.

An amending scheme which extended the pro@ visions of the 1931 scheme to coal miners emp ployed in any occupation underground was intro $\Phi$ duced in 1934 .

In 1935 Thomas, who the previous year had briefly referred to a type of case frequently en? countered amongst claimants in South Wales, enlarged on the topic from his additional experience in the interval. Many cases were encountered in the South Wales coalfield where the diagnosis was difficult for the following reasons. The industrial history and clinical findings led to the conclusion that a pathological process had developed which closely resembled silicotic fibrosis. Many of the men so affected were totally disabled. The skiagrams in most instances showed an abnormal condition of the lungs which, however, did not conform to the appearances generally accepted as including silicotic fibrosis. The films could be divided into three groups showing (a) emphysema only, (b) reticular fibrosis of a coarse type more or less evenly distributed, and (c) reticular fibrosis of a fine type more marked in the mid-zones. Similar cases had been noticed in the Manchester area, but it was not surprising when the Medical Research Council undertook an investigation of the whole problem in South Wales. After extensive investigations and a monumental report by D'Arcy Hart and Aslett, the Committee on Industrial Pulmonary Diseases accepted the view that dust was the fundamental cause of the 
abnormality, but as the relative parts played by the different components of dust had not been elucidated they were of the opinion that a nonspecific term should be used to describe it. They therefore recommended the use of the comprehensive term ' pneumoconiosis of coal workers,' and also recommended for purposes of compensation that the X-ray standard required for the diagnosis of pneumoconiosis of coal miners should include reticulation. Following this recommendation the Coal Mining Industry (Pneumoconiosis) Compensation Scheme came into force on July.I, 1943. It extended the application of the scheme to classes of workers not previously covered and empowered the medical boards to issue certiffcates in respect of a wider range of lung conditions caused by dust. It was always anticipated that the introduction of the new scheme and the widening of the definition which made it clear that one of the earliest stages of the disease came within the scope of the scheme would result in an increasing number of applications and certificates. Thus in I943 the board in West Wales examined 677 miners and certified 328 . In 1945 they examined 3,470 and certified 1,828 . Certification carried with it suspension from the industry, and the loss to coal mines through pneumoconiosis has been appalling. Between I93 I and 1943 seven men were leaving the South Wales pits every week suffering from silicosis, between 1943 and June, 1948, 50 men were leaving every week suffering from pneumoconiosis. The pool of pneumoconiotic ex-miners increased. These figures and this visible evidence etch in sharp and clear lines the coal problem and its associated medical problem. They have had other effects. They produced a real dust phobia in the mining communities; they tended to cause dissatisfied miners to rationalize all their superficial objections into fear of pneumoconiosis, and they have acted as a mighty deterrent to the sons of miners and others who might have entered the industry. It may be claimed that the figures igiven reflect the tragic legacy of mining conditions and the methods of mining over the last 30 years, but the marked increase in discovered cases in recent years certainly does not indicate a worsening in conditions. Between 1923 and 1940 the mines became deeper, drier and dustier. These were the years of mechanization. In the majority of mines conveyors were introduced from 1923 onwards. Pneumatic drills had been in use from about 1913 , but coal-cutting machines were not introduced until about 1927 and screening plants in 1934. All these intensified the processes and speeded up the evolution of the lesions in the lung. Before mechanization two colliers working the long-wall system would advance about three yards a week cutting and boxing coal, packing, stowing and ripping, doing productive and ' dead ' work. Witke conveyors, ro to 20 colliers work a face shovelling气 coal on to the conveyors, doing productive work practically the whole time. In these conditions $\mathbb{D}_{\infty}$ the air carries a heavier dust burden from the $e^{-}$ activities of a group of men. Occupational risk $\overrightarrow{=}$ here is intensified by the overall industrial risk. But these years were also the years of the X-rayc and its increasing use in the diagnosis of pul- $\frac{\bar{c}}{\mathrm{c}}$ monary disease. Already by 1932 many of the applications on behalf of coal miners in West 0 Wales were supported by X-ray reports. Largelyos following the pioneer work of Harper in Amman- $\vec{O}$ ford, some of the Miners' Lodges initiated a systemof periodic X-ray examinations by private radi- $\vec{\omega}$ ologists who, by 1943, were X-raying 4,000 to 5,000 miners each year. Many others were being $\mathrm{X}$-rayed by tuberculosis physicians. After the introduction of the 1943 scheme with its wider definition of pneumoconiosis there was a flood of ${ }_{0}$ applications to the medical boards, and in $1944^{\circ}$ the South Wales Miners' Federation directed that ${ }_{\infty}$ every claim should be supported by a radiologist's $\circ$ report. Thus was made general for South Wales. the practice which had been adopted in the western districts for many years. The filtering of applications withheld a large number of claims, $\frac{\mathbb{1}}{3}$ but it revealed evidence of pneumoconiosis thousands of others. In his first Goulstonign Lecture, Fletcher discussed the increase in ce्s-co tification rates after 1943 and considered the ma causes to be (a) the acceptance of the radiologicali condition of reticulation, (b) the operation of thes Essential Works Order, and (c) more general awareness of the disease and intensive mechanization introduced into the East Glamorgan pits. $\frac{2}{\mathbb{Q}}$ However, as the increase in cases certified as due to silicosis alone in 1943 was 75 per cent. higher, and in 1945 was 300 per cent. higher than the I942 figure, the admission of reticulation accounted for slightly less than half the increase. It is therefore reasonable to suggest that a striking 3 . increase would have been reported without thenew scheme, and that the alarming figures in 3 . South Wales arose mainly from what in fact be- 8 came a mass radiographical investigation. Experience has proved that the evidence of the diseaseo in any industry is proportionate to the number of $\mathrm{X}$-ray examinations made of the chests of workerso exposed to dusts as suggested by Rubin in regard to silicosis.

The figures in Tables $I$ and 2 underline some of the points discussed in the preceding paragraphs. N

\section{Incidence of Pneumoconiosis}

The incidence of the disease is firstly in colliers, $\frac{\infty}{\infty}$ then in firemen and shotsmen, repairers, hauliers, 
TABLE I

Pneumoconiosis and Silicosis in the CoAl Mining Industry

Number of new cases certified by the Silicosis Medical Board in Great Britain during the years 1939 to June 30 , 1948 (1948 figures are provisional)

\begin{tabular}{lll|r|r|r|r|r|r|r|r|r|r}
\hline \multicolumn{1}{r|}{ Region } & & & & 1939 & 1940 & 1941 & 1942 & $1943^{*}$ & 1944 & 1945 & 1946 & $\begin{array}{r}\text { Up to } \\
1947\end{array}$ \\
\hline Iune 30 \\
1948
\end{tabular}

* Pneumoconiosis Scheme.

TABLE 2

Pneumoconiosis in Coal. Mines

Cases Certified by Silicosis Medical Boards

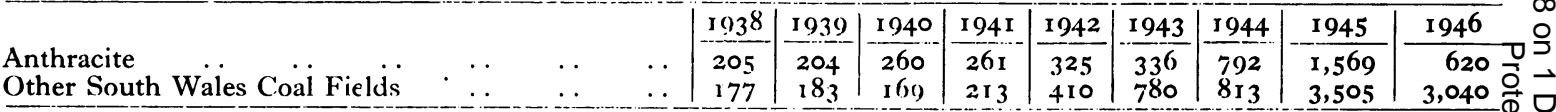

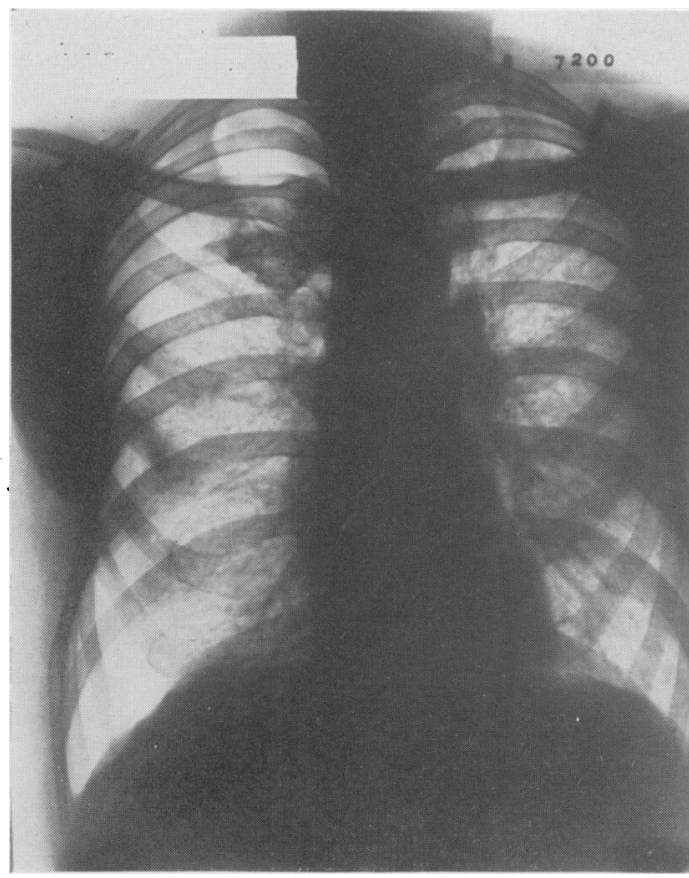

Fig. I.-J.W., aged 52 years; repairer 8 years; hard ground borer 7 years; rider 22 years; total 37 years. Ceased work because of sudden onset of dyspnoea. Pneumoconiosis Category 2 with spontaneous pneumothorax $(\mathrm{R})$.

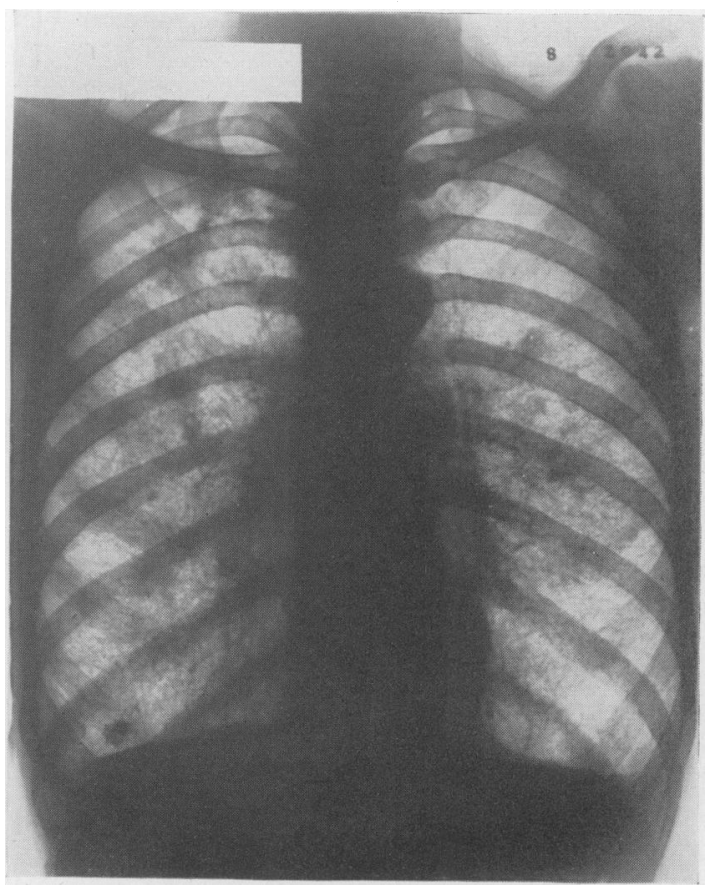

FIG. 2.-D.R., aged 5I years; repairer 7 years; collier 9 years; labourer 20 years; total 36 years. Pneumoconiosis Category $3 \mathrm{~A}$. 


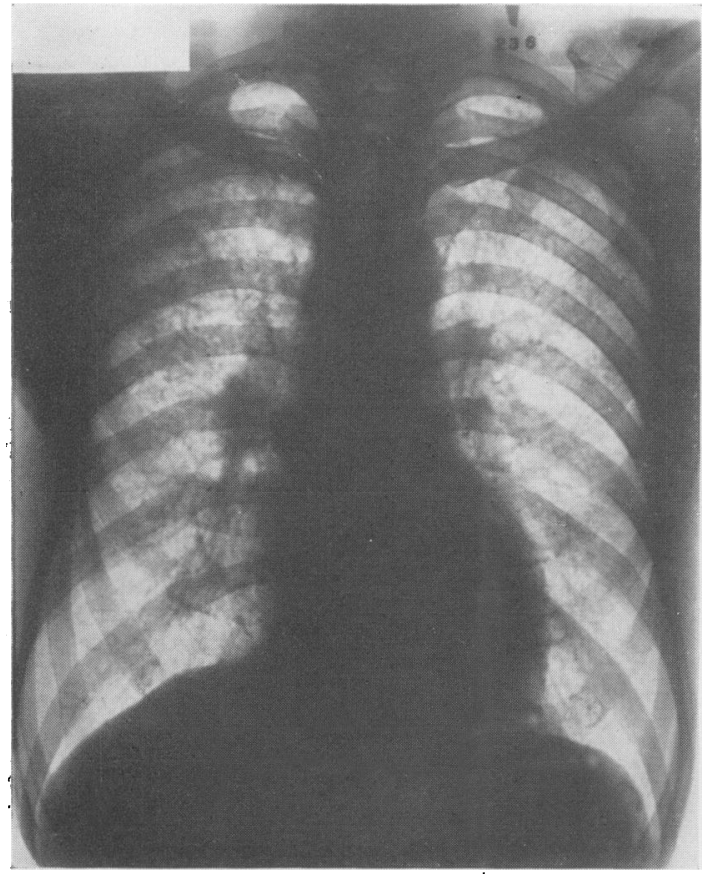

Fig. 3.-T.G., aged $3^{8}$ years; collier $2 \mathrm{r}$ years. Simple Pneumoconiosis, Category 3.

hard ground men, surface screen workers and underground labourers in this order. It requires for its development on the average I 5 to 20 years' exposure. Whereas 25 years ago the incidence appeared to be chiefly in borers and 'hardheaders,' in West Wales in the period 1943-1949 only an occasional case was seen where 'hardheading' was the attributable risk. This would appear to justify the claim of the owners that dust conditions in the hardheadings were as good as anywhere underground. An interesting fact emerges from an investigation of the incidence in hauliers. Thus the disease is fairly common in hauliers with exposures of 25 to 40 years in conditions prevailing between $1900-25$, but it is rarely, if ever, seen in hauliers with similar exposures in recent improved conditions. This reflects a reduction in air-borne dust in the main roadways. The incidence of disease in colliers in two collieries, $\mathrm{X}$ and $\mathrm{Y}$, with nearly equal population at risk has been investigated. These collieries were chosen because in both 90 per cent. of all the workers had been X-rayed by private radiologists. All those with definite X-ray abnormalities, with doubtful skiagrams and even

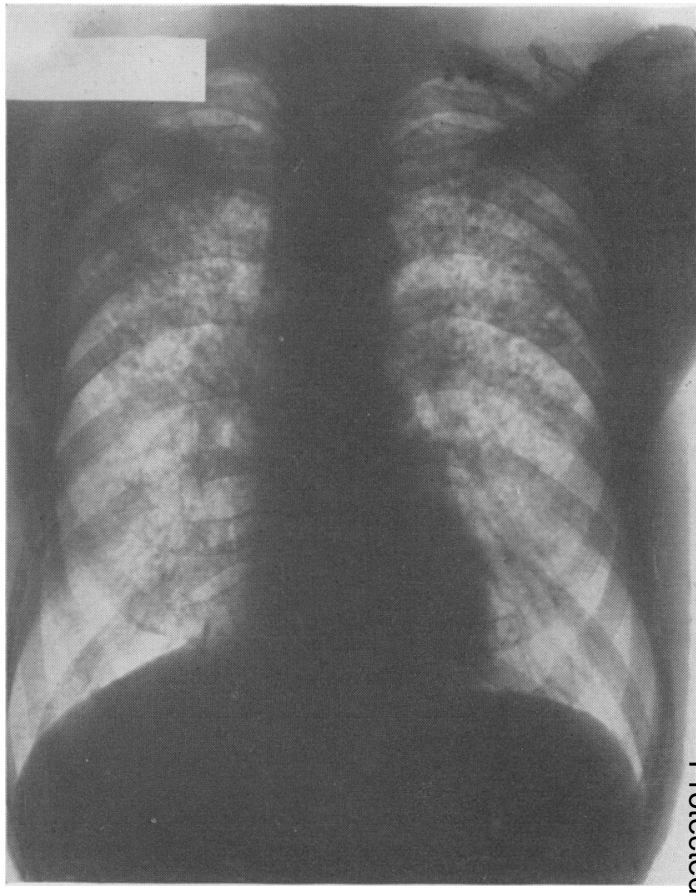

FIG. 4.-Same case, showing progression after months.

a few with negative skiagrams made applications to the medical board. It can be taken that the rest were completely negative. For the purposes $\stackrel{2}{\circ}$ of the investigation all those in which the disease $\stackrel{\unrhd}{\square}$ could not be wholly attributed to the particular $\overrightarrow{\overrightarrow{0}}$ colliery were excluded. The incidence and stage 3 of disease in age groups are shown and the ranking of the collieries as regards dust conditions is indicated.

The stages of the disease are based on Gough's classification in which he divided the pneumo- $\frac{5}{3}$ coniosis of South Wales coal workers into two main types (a) simple pneumoconiosis and (b) $\stackrel{\varrho}{2}$ infective pneumoconiosis. The term complicated pneumoconiosis is preferred here in order not음 to pre-judge the issue as to the exact causation $D$ of the condition-whether due to infection or to toxic action of siliceous dusts. (For details of the categories in each stage see ' $\mathrm{X}$-ray Examination.')

It will be seen from Table 3 that colliery $Y$ has 0 produced more disease than colliery $\mathrm{X}$ and, what is $\omega$ more important, it produces it in much earlier age groups. Thus it has produced pneumoconiosis inco 19 colliers under 30 years of age while colliery $X$ has produced only three in that age group. 
TABLE 3

\begin{tabular}{|c|c|c|c|c|c|c|c|c|c|c|c|c|c|c|c|c|c|c|c|c|c|c|c|}
\hline & & & & & & & & & Pn & $\begin{array}{l}\text { Si } \\
\text { eum }\end{array}$ & $\begin{array}{l}\text { nple } \\
\text { ocor }\end{array}$ & osis & & & & & & Pn & & & & & \\
\hline & tegc & & & & & & & & & & & & & & & & & & & & & 1 & \\
\hline $25-30$ & . & . . & $\ldots$ & $\ldots$ & . & 2 & 3 & 0 & 3 & I & 8 & 0 & 5 & 0 & 0 & 0 & $\circ$ & 0 & o & $\circ$ & o & 0 & o \\
\hline $31-40$ & . & . & . & . & . & 15 & 0 & 7 & 0 & 16 & 13 & I & 16 & 0 & o & I & 0 & 0 & 4 & $\circ$ & o & 0 & o \\
\hline $6 I-70$ & . . & . . & . . & . & . & 0 & 0 & I & 0 & 0 & o & 0 & I & 0 & 0 & 2 & 0 & 0 & o & I & o & 0 & 0 \\
\hline 70 & . & . & . . & $\ldots$ & . & & & & & & & & & & & & & & & & & & \\
\hline
\end{tabular}

Colliery X: Average depth, I,500 ft. Very dry. Satisfactory as regards dust concentration.

Colliery Y: Average depth, $850 \mathrm{ft}$. Very dry. Unsatisfactory as regards dust concentration.

The figures in the table seem to confirm the opinion of Jenkins (1948) that the incidence of simple pneumoconiosis so far as collieries are concerned, can be looked upon as a function of time -concentration of dust. If the incidence of disease in the under 30 age group is an index of dust conditions it is gratifying to report a marked improvement. Between I 943 and 1946 I I 5 cases were seen, but between 1946 and 1949 only 3 cases in the under 30 age group were found to have developed pneumoconiosis.

The duties of the Pneumoconiosis Medical

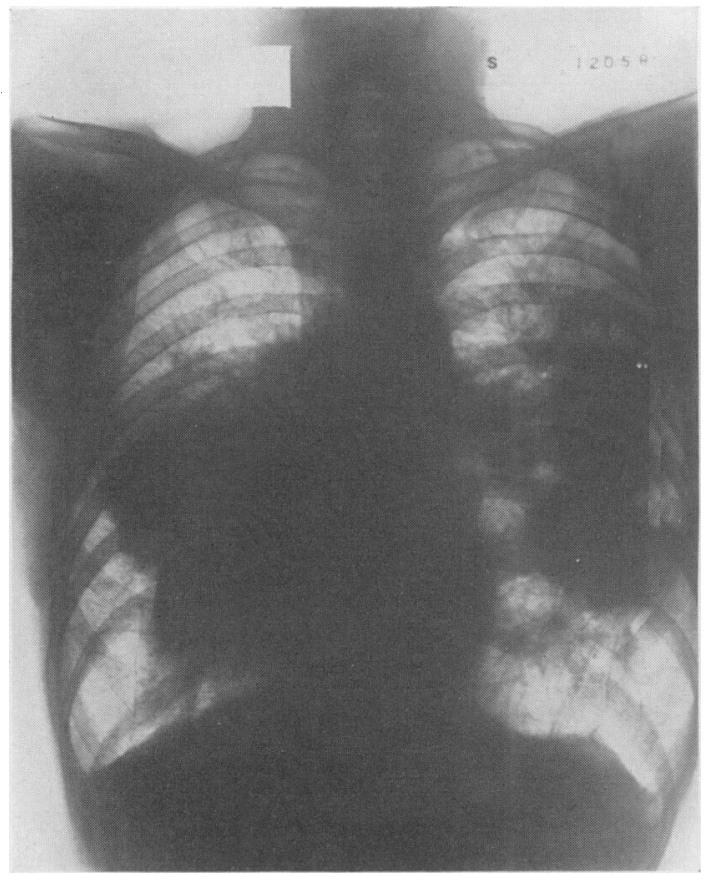

FIG. 5.-E.G., aged 4I years; collier I6 years. Complicated Pneumoconiosis, Category $3 \mathrm{D}$. Seen ro years previously the category of the $\mathrm{X}$-ray abnormalities was $3 \mathrm{~A}$.
Panels under the National Insurance (Industrial Injuries) Act include those that obtained under the Silicosis and Pneumoconiosis Schemes. They are mainly (I) diagnosis of the disease, and (2) assessment of disability. Now advisory functions are added; moreover assessment has to be determined on a percentage basis.

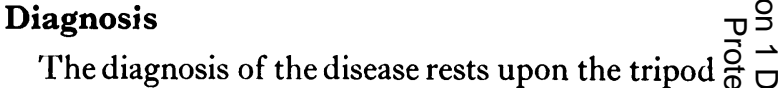
cited by Keating in 1930-industrial history, clinical examination and X-ray examination.

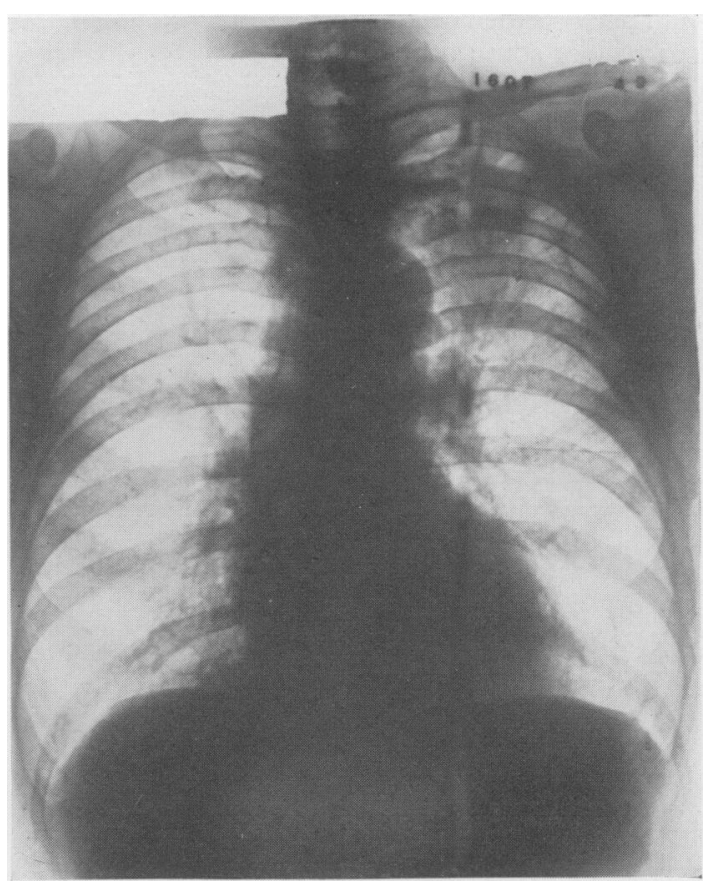

FIG. 6.--P.J., aged 57 years; repairer 23 years; collier I9 years; total 42 years. Tuberculosis per se. 


\section{Industrial History}

Meiklejohn (1949) has contributed a valuable paper on the importance of the care necessary in eliciting all the facts and he has emphasized that an expert knowledge of industrial processes is a necessary qualification of the pneumoconiosis expert. A visit to a working place underground is worth more than hours of questions and explanations in the examination room. In coal mining, as in other industries, the physician must think of occupational risk and of general industrial risk, of dust created in particular places and of general airborne dust. He should ask about intensity of exposure, about length of exposure and should enquire how far mechanization has proceeded. The attributable risk may have been in a job which the man considered not very important, especially if he had left it many years ago. The industrial history correctly ascertained is a matter of fact. In the presence of the specific X-ray signs of the disease it is the most valuable aid in establishing the diagnosis. In the presence of ambiguous shadows or other X-ray abnormalities, caution is necessary before basing a diagnosis on the most suggestive industrial history.

\section{Clinical Examination}

There is a tendency to regard clinical examination in pneumoconiosis as comparatively unimportant. This is largely due to the fact that the disease, like some other miliary nodular diseases, can only be diagnosed by radiological examination. In the writer's opinion, however, thoroughness is of paramount importance and a searching clinical examination is necessary for evaluation of the symptoms, for acquiring expert knowledge of the chest necessary in reading chest skiagrams, for differential diagnosis and for the assessment of disability. The methods of inspection, percussion and auscultation are by no means discredited.

\section{Symptoms}

At the outset it has to be stated emphatically that symptomatology is often unreliable and varies with the circumstances and outlook of the patient. Psychologically the attitude of the patient as a claimant is often quite different from those observed in other circumstances, and an objective appreciation is necessary. The first and the commonest symptom is 'tightness of the chest,' a term used by the majority to indicate slight breathlessness, and by the minority to indicate a feeling of constriction or difficulty in taking a deep breath. The tightness is often worse in the morning and in close, damp weather. 'Shortness of breath,' however, is often an understatement for moderate or even marked breathlessness. Though the onset of these symptoms as stated by the

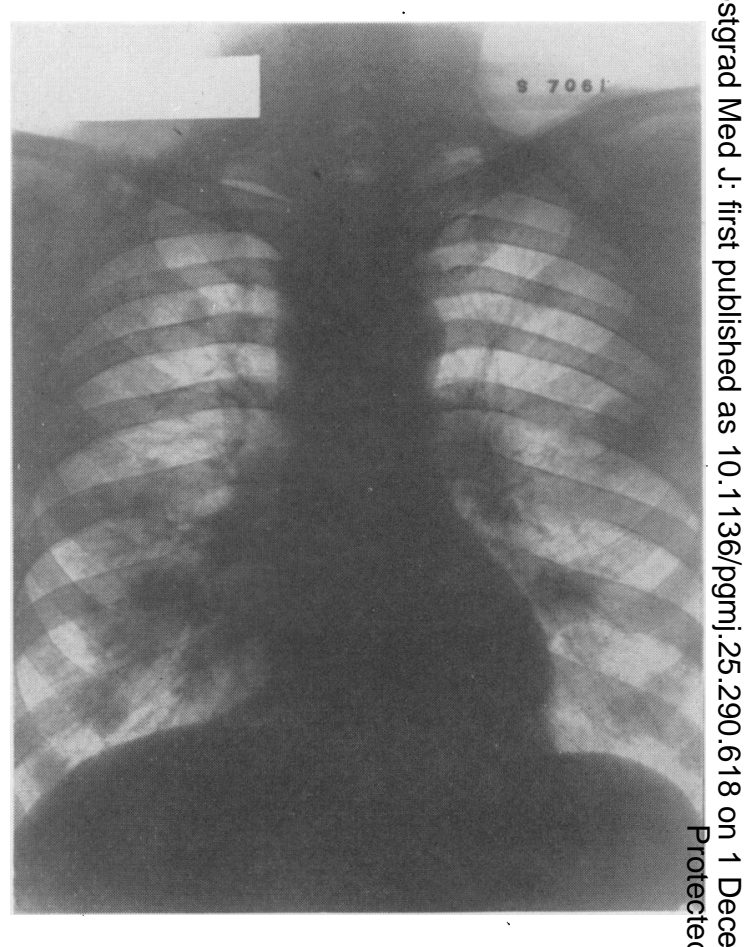

FIG. 7.-T.F., aged 34 years; colliery is years. Cage $\frac{\mathbb{D}}{3}$ of Hodgkin's disease confirmed at post-mortem 6 months later.

patient may be unreliable, the breathlessness rarely of recent origin. The patients themselves tend to grade the dyspnoea by the restrictions it imposes; some are 'all right on the level but bad on inclines,' some are ' worse on inclines,' while others have difficulty in remaining at work. Ex- $\frac{Q}{\Phi}$ cept in a minority of cases these symptoms are $\varrho$ compatible with regular employment and even $\overrightarrow{\overline{\vec{O}}}$ with overtime. A history of a change of occupation from a heavy job to a light job-from a wellpaid to a less well-paid-because of chest trouble, is stronger presumptive evidence of the presence of dyspnoea, and is often more valuable than a recital of symptoms.

Cough is second in frequency but it is rarely the chief symptom. It is usually a short cough, 3 occurring at night and on rising in the morning; 0 and it is not affected by weather changes. In the early stages of the disease the cough is not related $\frac{D}{0}$ to effort but with more advanced disease it is induced by exertion. When cough is the chief $N$ symptom, tuberculosis, bronchitis or emphysema N should be suspected.

The majority of the patients complain of $a_{\sigma}^{\omega}$ slight viscid sputum usually black or grey in colour and very few fail to supply a specimen $\stackrel{0}{0}$ when a sputum examination is directed. With the onset of infection the character and quality of the 
sputum changes, but even in the presence of characteristic chest signs and X-ray abnormalities it is very difficult to demonstrate tubercle bacilli in the sputum of coal miners. Of great significance is the sudden appearances of copious black sputum to which the Pneumoconiosis Research Unit have given the name 'melanoptysis.' It denotes the breaking down of a large fibrotic mass in the lung and has prognostic significance.

Pain is probably third in order of frequency and the most frequent site is behind the sternum. In most cases there are no physical signs to explain it. There seems to be no relationship to cough and it is often present without cough. Cardiac disease as the cause of pain must, of course, be excluded. Pleuritic pains are fairly frequent and, in a disease associated with superficial emphysematous bullae, spontaneous pneumothorax as a cause of sudden severe pain must not be overlooked. Pain in the lumbar regions is a frequent complaint and this may be due to irritation of the diaphragm.

Haemoptysis is rare and occurs with complicating tuberculosis, mitral stenosis or carcinoma of the lung. 'Stained 'sputum is often mentioned but its significance is doubtful. Sputum examinations in patients presenting this symptom have failed to demonstrate tubercle bacilli in a single case where physical signs in the chest were not also present.

Weakness is a very common complaint but is difficult to relate definitely to pneumoconiosis. Colliers' work is heavy and for years they have worked under conditions of strain; weakness may be due to other causes. Deterioration is slow, however, and marked alteration in the severity of the symptom is suggestive of tuberculosis or other serious disease.

Once the symptoms of pneumoconiosis are established they persist. There is no marked periodicity and seasonal exacerbation as in chronic bronchitis and, except in the rare occurrence of spontaneous pneumothorax, no sudden changes in severity occur as in tuberculosis and cancer of the lung.

\section{Signs}

The appearance of the patient may give no clue to the presence or severity of the disease. The average pneumoconiotic collier is fairly stocky with good muscular development. In the absence of extraneous disease obvious loss of weight suggests tuberculosis or gross emphysema. Unilateral contraction and tracheal deviation also suggest tuberculosis. Cyanosis is rare and is seen only in cases of gross emphysema or cardiopulmonary disease. Marked pallor may be observed where infection has supervened and its presence calls for a careful examination of the abdomen and of the haemopoietic and lymphatic systems. Finger clubbing is not seen in simple pneumoconiosis of coal miners, but in complicated pneumoconiosis it occurs in cases with bilateral basal confluent opacities and with open tuberculosis.

When dyspnoea is demonstrable it is invariably associated with some loss of the mechanical bellows action of the chest. The average collier, with or without pneumoconiosis, does not use his chest well and it is therefore difficult to detect the first signs of departure from the normal. This is seen in more rapid shallow breathing with limited diaphragmatic movement. With more marked dyspnoea and increasing fixation of the chest, the movements of the diaphragm become vigorous. The respiratory rate is not always increased, for an asthmatic type of breathing with prolonged and laboured expiratory phase is associated with massive fibrosis, as these cases seem to have a good deal of spasm. In pneumoconiosis with extensive bullous or focal emphysema the extreme phase is reached; there is marked rigidity of the chest which is held in the position of inspiration, with contraction of sternomastoid, pectoral, intercosta $T^{\circ}$ and abdominal muscles, and laboured breathing Tuberculosis should be suspected in those cases? with considerable dyspnoea not associated with $\mathscr{Q}$ marked rigidity, and unequal movements should suggest pleurisy, pneumonia or tuberculosis. Until the onset of cardiac failure in the advancedo stages of the disease the dyspnoea of pneumo coniosis always subsides on rest. In the terminal? phase the signs and symptoms do not differ from those of classical right heart failure.

\section{Percussion}

In the early stages there is no change to percussion. Later there may be impairment of the note over the upper and mid-zones. Differential impairment of percussion in the upper part of one lung is suggestive of tuberculosis. Very frequently even when the upper and mid-zones show impairment, the note in the axillae and over the lower lobes is hyper-resonant due to underlying emphysema, and in such cases cardiac dullness may be diminished.

\section{Auscultation}

Auscultatory signs are often present before percussion signs. The cardinal sign is a modified, rather high-pitched respiratory murmur best heard in the right lung in the axillary area. Over the apices and upper parts of the lungs the murmur may be normal. In the majority of moderatelyadvanced and severe cases the breath sounds are diminished at the bases and a feature of the case showing massive fibrosis is the presence of silent 
areas over the upper lobes posteriorly. Signs of bronchitis and bronchiolitis are fairly frequent in complicated pneumoconiosis but not in simple pneumoconiosis. Sibilant rhonchi are heard in the axillae and at the bases, and superficial crepitations at the periphery of the lungs. The presence of tuberculosis will introduce the innumerable physical signs by which it betrays itself. Although dense pleural adhesions are so frequent at postmortem examinations pleural friction is rarely heard in life. Except in the advanced stages of the disease there are no cardiac changes detectable, and until those stages are reached the electrocardiogram shows no change. In what has been called the ' cardiac phase,' however, the cardiac sounds are weak and the E.C.G. shows right-sided preponderance.

\section{$X$-ray Examination}

Diseases of the lung cause either increased or decreased aeration reflected radiographically by increased or decreased translucence. Increased translucence is found chiefly in the emphysematous states. Decreased aeration is caused mainly by fluid, secretions and by diffuse and nodular fibrosis. The resulting loss of translucency is reflected in terms used by chest physicians and by radiologists, ' snowstorm,' ' snowball,' ' sausage mass,' ' pseudo tumorale,' ' cotton wool,' ' pin point,' ' pin head,' etc. Professor Gough, whose work has conspicuously clarified our ideas on the subject, deals with the nature and pathology of the disease in his contribution. It is sufficient here to recall that the retention of particles of dust in the lungs when intake exceeds output, when the dust fails to reach its physiological destination and is effectively retained in the lungs, results in small collections of dust, i.e. coal nodules. It may be expected, therefore, that certain properties of the dust, namely, particle size, dosage, toxicity and radio opacity will influence the $\mathrm{X}$-ray picture. It is doubtful, however, whether particle size does more than determine admission to lung alveoli and liability to phagocytosis in the alveoli. It has been suggested that difference in particle size resulted in coal particles and silica particles reaching separate destinations in the lung, so producing different X-ray pictures, but Enid Rogers has shown that the earliest coal nodule and the earliest silicotic nodule appear in the same site, i.e. in the lymph tissue at the junction of the respiratory bronchiole and alveolar duct. The effects of dosage are not difficult to understand. The capacity of certain alveolar cells to remove dust is one of the chief mechanisms for cleansing the lungs, but when the load is too heavy for the phagocytic 'ride' the mechanism breaks down and dust is trapped in the lungs, it may be in only one or two lobules or, with more massive doses, in lobules throughout the lung. The effect of toxicity of dust particleș is not completely understood and it is too big $\mathrm{a}^{\mathrm{P}}$ subject to elaborate here. But it is possible to explain the differences in the histology and path ology of the coal nodule and silicotic nodule (which develops in the same site) by mechanical effects of masses of coal dust in the one and by the slow fibrogenic action of dissolved silica in the other든 Coal dust is said not to be radio opaque but? Gough, James and Wentworth have shown that there is a very close correlation between the $\mathrm{X}$-raye opacities of simple pneumoconiosis and the coal? nodules (with their minimum of reticular fibres) $\vec{\circ}$ The coal nodules are really collections of coal dust. $\vec{T}$ Some standard of what constitute a disease is demanded, otherwise legislation may becomed punitive and workers told unnecessarily and wrongly that they have the disease. Such and standard must have some relationship to the accumulated knowledge and experience of patho- 0 logical changes with special reference to inceptionos and development. The reading of $\mathrm{X}$-ray films mayo appear to be a routine process, but it requires longo experience in reading normal films, knowledge $\delta \mathrm{f}-$ occupations and risks, personal knowledge of the

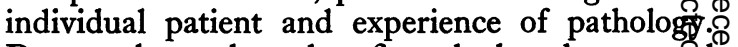
Doctors know by what fine shades the normas passes into the abnormal and in this regard theo "normal' chest admits of some departure from the normal. It can be stated that in the majorty of cases of simple pneumoconiosis the $\mathrm{X}$ appearances reflect the actual dust in the lungs; Tho a few they show certain associated changes, i.e.S emphysema in addition. In complicated pneumo-⿳亠二口犬 coniosis the X-ray appearances reflect the dust and\% fibrotic reaction to the dust and/or tuberculosis. $\mathbb{Q}$

It is not surprising that there have been many $\overrightarrow{\vec{B}}$ attempts to draw up a radiological classification for $\overline{3}$ pneumoconiosis. Some were unsatisfactory be-? cause they sought to combine stage of disease witho disability and some because they did not describe what was seen in the X-ray. In 1947 Davies and 3 . Mann published their suggested classification of the basic lesions, stages, categories and X-ray. types in South Wales. There is no doubt thato their classification is the best available and should 2 be studied by those interested. The authors? appreciated that pneumoconiosis varies in its $>$ radiological manifestations from country to country․ and from industry to industry and that the diseasen found in South Wales needed its own classification. Their classification is capable of wider application for radiologically coal miners' pneumo- $-\omega$ coniosis is the same disease in South Wales, Scotland, Durham, Lancashire and the Midlandsso There may be a geographical variation in the relative incidence of simple and complicated $\stackrel{\oplus}{+}$ 
TABLE 4

\begin{tabular}{|c|c|c|}
\hline \multicolumn{2}{|c|}{ Simple Pneumoconiosis } & Complicated Pneumoconiosis \\
\hline $\begin{array}{l}\text { Category } 0 \\
\text { Category I } \\
\text { Category } 2 \\
\text { Category } 3\end{array}$ & $\begin{array}{ll}\ldots & \text { Normal } \\
\ldots & \text { Minimal } \\
\ldots & \text { Moderate } \\
\ldots & \text { Marked }\end{array}$ & $\begin{array}{l}\text { A. Localized ambiguous shadows } \\
\text { B. Massive shadows } \\
\text { C. Advanced massive shadows } \\
\text { D. Advanced massive shadows with distortion of thoracic structures and emphysema }\end{array}$ \\
\hline
\end{tabular}

pneumoconiosis, as indeed there is in different pits in the same county, but examination of skiagrams from all the coalfields justifies their hope that the principle and broad outline of their classification will be applied to pneumoconiosis elsewhere. Gordon Smith is of the opinion that it is the same disease as is encountered in the New South Wales coal mines.

The Davies and Mann classification emphasizes that the basic radiological abnormalities in South Wales coal miners are minute opacities, 0.5 to I.5 $\mathrm{mm}$. in diameter (the term micro-nodular used by the French writers is very descriptive but it is better to keep to two-dimensional words). It abandons the general use of the term reticulation, it provides an instant picture in the mind's eye of the anatomic character of the parenchymal disease, it suggests the presence or absence of infection, it indicates distortion of thoracic contents, and it does not attempt to relate disability to any category nor does it define disease. The essentials of the classification are as follows:-In simple pneumoconiosis there are four categories of increasing abnormality, the distinction of categories being made chiefly on profusion of the opacities, the involvement of the periphery of the lung field and the degree of obscuration of the lung markings. In complicated pneumoconiosis there are also four categories, the distinction here being made in type or quality of the opacity. Thus the categories are as in Table 4.

In simple pneumoconiosis larger opacities, 1.5 to $5 \mathrm{~mm}$., of varying density and outline are also seen, and many of the pictures are of mixed types.

Several aspects call for further consideration. In simple pneumoconiosis screening of hundreds of cases has shown that the lungs are generally mobile, in contrast to lungs with complicated pneumoconiosis where diaphragmatic excursion especially, is limited. Enlargement of mediastinal glands is not a feature of simple pneumoconiosis. The granular opacities are usually bilateral but are often more profuse in the right lung, especially in the middle zone. They are rarely seen above the clavicle. Certain factors, however, may determine the concentration of the granules. In several cases with a history of left-sided pneumonia the concentration of granules has been in the left lung, while an active bronchitis of the right lung pre- vents the normal selective concentration on that side. These observations suggest that the features of these two pictures are due to decreased or increased phagocytosis. In category 3 especially, areas of close aggregation of the nodules is frequently seen in the middle longitudinal third of the lung, suggesting sometimes a ghost-like outline of a massive shadow.

Studies of progression have been very limited because under the former Compensation Schemes the majority of certified miners were not seen again. However over 500 colliers who returned to work underground after being found to have simple pneumoconiosis but no disability, have been re-X-rayed at intervals during the last six years. Davies and Mann state that progression in this stage of pneumoconiosis is by increase in the number of the opacities, but in the period men tioned above it has been practically impossible to demonstrate a single case of progression by in crease in numbers. Progression in this way io therefore slow, and the writer questions whether more than a small minority pass through all the categories, $\circ$ to 4 , and suggests that it is possible that category 3 may follow immediately on category $\circ$ or category $I$ through a sudden breakdown in the dust cleansing mechanism of the lung. Progression is fairly frequently recognized, however, in simple pneumoconiosis by the appearance, often in the outer third of the upper zone of the right lung, of larger opacities, 5 to $7 \mathrm{~mm}$. in diameter, but this heralds the new stage of complicated pneumoconiosis. Progression may be seen in the X-ray by a decrease in the opacities owing to focal emphysema becoming confluent. Emphysema in simple pneumoconiosis is suggested by increased translucency of the inner half of the lung field, low position of the diaphragm, flattened ribs and especially in one type of skiagram which reveals a fine reticular network like a $D$ cobweb with fairly sparse, evenly distributed granular opacities. This is the only type of film to $N$ show reticulation and the patient is usually over 40 years of age. The only cardiac change worthy of note is a prominent pulmonary conus seen fairly $\mathrm{\omega}$ frequently in cases where clinically there is gross emphysema. Occasionally due to rotation of the organ, concentric enlargement appears in the skiagram as an enlarged left ventricle. 


\section{Complicated Pneumoconiosis}

As already mentioned diaphragmatic excursion is often limited. Mediastinal glands are enlarged and fibrotic. Of the various opacities found in complicated pneumoconiosis, first in order of frequency is the single ambiguous shadow in the right upper zone just below the clavicle. Its edges may be blurred or sharply defined, and it rarely exhibits the linear drainage markings of old infection. Second in frequency are homogeneous shadows of varying shape, tangerine or reniform, and occasionally triangular. They may appear singly or in both lungs, and frequently two, three or even four appear in the same lung. They show a predilection for certain sites. Thus the commonest site is the right upper zone below the clavicle, the next in order of frequency is the midzones of the lungs above and below the inter-lobar septa. They are often found adjacent to the hilar structures and in the lower lobes and occasionally they show circumferential calcification. These, the 'pseudo tumorale' forms of the French writers, have been carefully studied by Balgairies and his colleagues who, with Leclercq, found by tomography. that the commonest sites were in the ' superior axillary' and 'middle dorsal ' segments of the lung. Another frequent picture is that of a number of irregular, sometimes fluffy shadows in the middle longitudinal third of the lung. There have been better opportunities to study the evolution and progression of these opacities, for the schemes under which the majority of miners with this stage of pneumoconiosis were certified have been in force for many years. They are associated with increasing disability and the men have returned for re-examination. Although these opacities are usually superimposed upon simple pneumoconiosis categories 2 and 3 , they are found also in categories 0 and 1 . They arise by at least two different processes. In discussing progression in simple pneumoconiosis, the appearance of clusters of larger opacities in the upper zone was described as the development of complicated pneumoconiosis. Such opacities may increase in numbers down to the mid-zone and to the base on the same side and to the mid-zone contralaterally, and they may then become closely aggregated and later confluent in the sub-apical region and mid-zones. Or the opacities may appear suddenly, often after illness such as bronchopneumonia and influenza, and in the site of an old fibrotic lesion. Continuing progression is associated with contraction and increasing opacity of the shadows, peaking of the diaphragm, and the disappearance of small opacities from the lower mid-zones. The latter is explained by the development of compensatory bullous emphysema, reflected in the X-ray by large translucent areas sub- divided by crescentic lines and shadows which occasionally give a 'soap bubble' effect. The onset of open tuberculosis will modify the appear-은 ance of the opacities and this will be discussed in the next paragraph. Radiological progression ${ }_{c}$ under dust exposure after certification and sus- $\Rightarrow$ pension from the industry has been carefully investigated by the Pneumoconiosis Researcho Unit. Fletcher found that the results of their흘 radiological surveys strongly suggested that the $\frac{\bar{\rho}}{\frac{1}{2}}$ development of complicated pneumoconiosis is $\underset{\Omega}{\Phi}$ due to some factor other than the addition of further dust to the lungs.

The cardiac shadow may become narrower as. the disease progresses, with or without the onset $\vec{\omega}$ of open tuberculosis.

\section{Differential Diagnosis}

It will be seen that the abnormal shadows found in pneumoconiosis resemble certain main forms of i tuberculosis of the chest. Thus the opacities of simple pneumoconiosis resemble those of the 9 nodular form of tuberculosis due to haemato- $\infty$ genous spread of tubercle bacilli. This may occuw without a fatal outcome. In miliary tuberculosis the patient is usually very ill. In healed milian $\mathbb{D}$ disease some of the opacities are calcified, th $\$$ glands are enlarged and the Mantoux test wouk $\bar{\sigma}$ help to establish the diagnosis. Sarcoid disease may also closely resemble simple pneumoconiosis but examination of the skin and bones-especialti. the hands-would confirm the diagnosis.

In low-grade broncho-pulmonary tuberculosis the commonest site of the lesion is in the apex of the lung. The patient may be symptomless, and in the presence of an industrial history diagnosis may be in doubt. Opacities above the clavicle and in the inner third of the upper zone, in the sterno-clavicular angle, especially if they are unilateral, veiling of the pleura, radiating fibrous bands and signs of cavitation all suggest tuberculosis. In fibro-caseous tuberculosis where conglomerate and irregular dense opacities and streaks are the feature, and where spread is to the base on the same siae and to the mid-zone of the opposite side, the picture may closely resemble moderately advanced pneumoconiosis. The presence of cavities in the X-ray, sputum and clinical examinations help to establish the diagnosis.

In certain other conditions, namely in coccidi- 을 oidomycosis and other fungus infections, in miliary $N$ and lymphatic metastatic carcinoma, in leukaemic $N$ conditions, and haemo-siderosis found in mitral $\mathcal{N}$ disease of the heart, the X-ray picture closely re- $\omega$ sembles that of simple pneumoconiosis. The opacities in complicated pneumoconiosis may be $\stackrel{0}{\subset}$ simulated by carcinoma, Hodgkin's disease, hyda- $\mathbb{\complement}$ tid cyst, thickened pleura or bronchiectasis. Thus 
a complete clinical examination is necessary, with special attention to haemopoietic and glandular systems with dermal tests if necessary and with skiagrams in oblique and lateral positions.

\section{Disablement}

The present Act like the former Compensation Schemes refers not to accident or disease but to personal injury by accident or disease; thus, under the provision of Section 12 of the National Insurance (Industrial Injuries) Act, 1946, an insured person is entitled to disablement benefit if, as the result of the relevant personal injury, he suffers loss of physical or mental faculty which is substantial and likely to be permanent. Whatever loss of faculty the claimant sustains he will suffer ' some disability' from which the normal person of the same age and sex will be free. The term ' disablement' is used to denote the aggregate of the disabilities which arise in a particular case-that is the aggregate loss of health, strength and the power to enjoy life. In simple pneumoconiosis it is the emphysema, focal and bullous, which results in unequal ventilation with insufficient oxygenation of blood. Massive fibrosis also results in insufficient oxygenation of the blood by reduction of the capillary bed. The anoxia results in a disability-dyspnoea, defined by Meakins as 'the consciousness of the necessity of increased respiratory effort,' and a disability recognizable by the observer. Definition of disablement in pneumoconiosis or at least its physical component is easy, but the assessment of disability remains a formidable problem. To the writer it presented itself in this way. In the early years, 1930 to 1943 , in South Wales and later in Lancashire, Durham and Scotland, claimants appearing before the medical board were obviously dyspnoeic, either at rest or after slight exercise. The loss of faculty was demonstrable and required no postulating, but clinical examination was necessary to determine whether the dyspnoea was respiratory, cardiac or both. After 1943, in the great rush of applicants to the board, the majority of claimants exhibited no objective evidence of disablement, though some of them were found to have well-established pneumoconiosis. There was the other side of the picture. When examining claimants the following type of case was frequently met-a youngish man, usually under 40 years of age, complaining of dyspnoea on exertion, often borne out by the occurrence of dyspnoea and sometimes vertigo after a short exercise tolerance test, rapid pulse (over 80 at rest), and obvious nervous demeanour. To the non-medical mind, such a man was not fit to do heavy work. If the skiagram of this chest showed simple pneumoconiosis, he would be assessed and suspended from the industry; on the other hand, if his skiagram was negative his claim would be refused, and he would return to work. The point to be stressed is that there was seldom any difference clinically between the positive and negative cases. One suspects that many of these cases exhibited the classical effort syndrome and that the finding of X-ray abnormalities was coincidental. The $\mathrm{X}$-ray is of very little value in the assessment of the individual case. Although we have learned by experience that the pathological extent of disease in massive fibrosis is often in advance of the X-ray signs, the skiagram does give a picture of the anatomical extent of the disease. But it is the functional capacity of the remaining healthy lung or partly damaged lung which allows a man to enjoy life and to make his respiratory adjustments albeit at the expense of respiratory reserve. When the reserve is spent, even slight progression in the disease will result in inexorably increasing dyspnoea.

The effects of emphysema in producing a respiratory ' dead' space with unequal respiration have been noted, and there is no doubt that emphysema which, in some forms at least cannot be ${ }_{0}$ estimated by the X-ray, causes more dyspnoea than even large areas of fibrosis. It is obvious, too, $\stackrel{\mathbb{D}}{\mathrm{D}}$ that there is a mechanical ventilatory component $\widetilde{\Phi}$ of pulmonary insufficiency. Observation of thousands of cases has shown that in the dyspnoea of pneumoconiosis, ventilatory insufficiency plays a conspicuous part, and this is another reason why it is impossible to correlate disablement with the $\mathrm{X}$-ray picture. The effects of pleural adhesions and of fixation of the chest cannot be estimated by the X-ray. But the X-ray has a 'group' or ' average 'value, and in that way may be an aid in assessment. McCann, Hurtado, Kaltreider and Fray applied physiological tests to a series of pulmonary fibrosis cases divided into groups according to the anatomical type of fibrosis revealed. They concluded that the average value of the changes were proportional to the degree of fibrosis. Camazian (fils) investigated medico-legal decisions (percentage awards) in 706 pneumoconiotic miners in the Cevennes and came to the conclusion that, in general, functional capacity was in proportion to the X-ray lesions. Experience in South Wales confirms these general observations but the individual variations in each group and the peculiar difficulty of diagnosing focal emphysema must be stressed.

The approach to assessment of disability then is made on the recognition of certain principles.

r. A complete clinical and X-ray examination and, if necessary, a second or third examination. The close association of certain ' chest ' symptoms with cardiac and cardio-vascular diseases must constantly be borne in mind. 
2. The effects of emphysema, focal and bullous, must be included in the disease.

3. Dyspnoea is recognized and demonstrated, and assessment in the individual case is mainly on clinical judgment, aided by exercise tolerance tests or other physiological tests:-

(a) The exercise tolerance test is standardized.

(b) The response to the test depends upon many factors, bronchial spasm, pleural adhesions, 'fixed' chest, and the assessment is not further loaded by the presence of these conditions.

(c) The dyspnoea demonstrated is divided into several grades with a percentage value for each grade.

4. Ideally the X-ray should not be used in assessment, but in the absence of an ideal or practical physiological test, the assessment is increased by adding percentages according to the degree of fibrosis.

(Members of the Penumoconiosis Medical Panels are at present measuring vital capacity, maximum breathing capacity and minute volume on exercise by means of apparatus kindly supplied by Dr. J. G. Gilson and Dr. P. Hugh-Jones, Pneumoconiosis Research Unit, who advised on the standardization of the exercise tolerance test.)

In the period 1943 to 1949,20 per cent. of all applicants found to have pneumoconiosis had no disablement. This percentage is made up chiefly of coal miners with simple pneumoconiosis categories 2 and 3, for in these stages at least 36 per cent. have no disablement. When disability is found it is due to the presence of focal emphysema or infection. A few cases with complicated pneumoconiosis are found to have no disability, but the majority have varying degrees of disablement, again depending on the extent of emphysema, fibrosis and the presence of tuberculosis. Thus these two conditions, emphysema and tuberculosis, dominate all our studies of the $\stackrel{0}{0}$ disease.

\section{Deaths from Pneumoconiosis}

In Great Britain during the eight years $1940 \stackrel{\circ}{\circ}$ to 1947 , there were an average of 530 deaths each $C$ year from pneumoconiosis. Coal miners accounted $\overrightarrow{\vec{F}}$ for more than half the annual figure. In a valuable study of pneumoconiosis in South Wales anthra- $\frac{-}{0}$ cite mines, Gooding made an analysis of $592 \overline{\bar{c}}$. deaths among certified silicotics. He found that $\widetilde{\widehat{ }}$ $5^{16}$ in the series were due to silicosis and 76 to extraneous causes. Of the 'silicotic' deaths 145, क or 28.I per cent., were due to silicosis accompanied $\vec{\circ}$ by tuberculosis. The writer has similarly investigated 300 deaths where full details were avail- $\omega$ able and has divided them into two groups accord- $\overline{0}$ ing to the stage of the disease. The great majority 3 of deaths from pneumoconiosis and pneumo-i coniosis accompanied by tuberculosis are from or congestive right heart failure, and tuberculosis is 0 given as the cause only when haemoptysis occurred or when severe toxaemia and wasting were present. .0 When tuberculosis was present, however, it waso recorded (see Table 5).

In this series 183 deaths were due to the diseageo and II7 to extraneous causes. In the first grou 'pneumoconiotic' deaths accounted for 22 pero cent. and in the second group 76 per cent. of the total. Simple pneumoconiosis is not a killieg disease like complicated pneumoconiosis. Analysiss of the deaths from complicated pneumoconio $\mathrm{mis}^{\mathrm{s}} \mathrm{O}$ shows two chief sub-groups, those diagnosed with category $B$ and $C$ in the 30 to 40 age group and those diagnosed in the 60 to 70 age group. In the first the average period between certification and death is five years, in the second it is six years. $\mathbb{D}^{\circ}$ As it may be assumed that many of those in the $\overrightarrow{\vec{F}}$ latter group must have developed complicated? pneumoconiosis at a much earlier age, it follows -
Pneumoconiosis (C.H.F.)

Pneumoconiosis Accompanied by Tuberculosis (C.̈.H.F.)

Tuberculosis

Spontaneous Pneumothorax ..

Pneumonia

Sclerotic, Hypertensive and $\ddot{D}$ egenerative Heart Disease

Valvular Disease of the Heart

Bronchial Carcinoma ..

Cancer (Other Organs)

Uraemia

Weil's Disease.

Miscellaneous Causes .. Total
.

$\cdot$

$\cdots$

..$$
\vdots
$$$$
\begin{aligned}
& . \\
& . \\
& . \\
& . \\
& .
\end{aligned}
$$$$
\text { .. }
$$$$
\text { . }
$$$$
\text { - }
$$$$
\cdots
$$$$
\cdots
$$$$
\cdots
$$$$
\cdots
$$$$
\text { .. }
$$

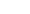

$\begin{array}{lll}. & & \\ & . & \\ & . & \end{array}$

. $\quad \ldots \quad \cdots$

$\begin{array}{lll}\cdots & \cdots & \\ \cdots & \ldots & \end{array}$

$\begin{array}{lll}\cdots & \cdots & \cdots \\ \cdots & \cdots & \cdots \\ \cdots & \cdots & \cdots\end{array}$

$\begin{array}{lll}\cdots & \cdots & \\ \cdots & \ldots & \end{array}$

․ $\quad \ldots \quad \ldots$

$\begin{array}{lll}\cdots & \ldots & \ldots\end{array}$

$\begin{array}{lll}\cdots & \cdots & \cdots \\ \cdots & \cdots & \cdots\end{array}$

$\begin{array}{lll}\cdots & \cdots & \cdots\end{array}$

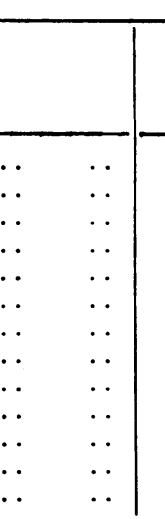

\begin{tabular}{|c|c|}
\hline $\begin{array}{l}\text { Simple } \\
\text { Pneumo- } \\
\text { coniosis }\end{array}$ & $\begin{array}{c}\text { Complicated } \\
\text { Pneumo- } \\
\text { coniosis }\end{array}$ \\
\hline I6 & 98 \\
\hline 2 & 60 \\
\hline $\mathbf{I}$ & 4 \\
\hline To & $\begin{array}{l}2 \\
7\end{array}$ \\
\hline 18 & 14 \\
\hline 2 & 2 \\
\hline I & 3 \\
\hline 13 & 6 \\
\hline 5 & 4 \\
\hline 18 & 12 \\
\hline 86 & 214 \\
\hline
\end{tabular}


nevertheless that a considerable number of men who develop complicated pneumoconiosis when aged 30 to 40 are a very bad risk. Tuberculosis was present in 36 per cent. of all pneumoconiotic deaths, in 16 per cent. of all deaths due to simple pneumoconiosis, and in 39 per cent. of all deaths due to complicated pneumoconiosis. The figure ( 36 per cent.) of the extent of complicating tuberculosis in coal miners' pneumoconiosis is higher than the figure given by Gooding and others, but it is considerably lower than the figure for other industries, especially for slate mining in North Wales where tuberculosis is present in 75 per cent. of pneumoconiotic deaths.

Finally, one is impressed by the apparently increased susceptibility of coal miners with simple pneumoconiosis to pneumonia and acute respiratory infection.

\title{
BIBLIOGRAPHY
}

BALGAIRIES, E., DECLERCQ, G., JARY, J., and NADIRAS, P. (1948), Revue Medicale Miniere, 2, 12.

CUMMINS, S. LYLE, and SLADDEN, A. F. (1930), F. of Path. and Bact., 33.

CAMAZIAN (FILS), PIERRE (1947), 'Recherches Sur Les Pneumokonioses Dans Les Charbonnages.'

DAVIES, I., and MANN, K. (I948) 'Proceedings of the Ninth International Congress on Industrial Medicine.' (In the press.)

FLETCHER, C. M. (1948), Brit. Med. F., 1, 101 5, 1005

GOODING, C. G. (1946), Lancet, 2, 891 .

SMITH, GORDON, Personal communication.

GOUGH, J., JAMES, W. R. L., and WENTWORTH, J. E (1949), "A Comparison of the Radiological and Pathological Changes in Coai Workers' Pneumoconiosis,' Fournal of the Faculty of Radiologists, I, I.

GREGORY, J. C. (1831), Edin. Med. and Surg. Fournal, 36, 389. GRENFELL, D. R., Personal communication.
HART, P. D'ARCY, and ASLETT, E. A. (1942), Special Report Series, M.R.C. No. 243 (B).

JENKINS, T. H. (1948), "Medico-Mining Aspects of Pneumoconiosis in South Wales.' Paper read before' the South Wales Institute of Engineers.

KEATING, N., Personal communication.

LECLERCO, J., BALGAIRIES, E. BONTE, G., and DECLERCQ, G. (1948), Revue Medicale Miniere, 4, 23.

MCCANN, HURTADO, KALTREIDER and FRAY (1937), Fourn. Clin. Invest., 16, 23.

MEIKLEJOHN, A. (r949), Lancet, 2, 360, 'Contribution of the Employment History to Clinical Diagnosis.'

ROGERS, ENID (1944), Paper read before the Tuberculosis Association.

RUBIN, EI.I H. (1947), 'Diseases of the Chest,' W. B. Saunders and Co.

TATTERSALL, N. (1926), F. of Indus. Hygiene, 8, 466.

'IHOMAS, R. W., Personal communication.

\section{ASBESTOSIS}

\author{
By H. Wyers, M.A., M.D., D.I.H.
}

Although certain difficulties remain to be explained, the theory that silica is a causative agent in pulmonary fibrosis is widely accepted. When, however, the fibrogenic potentialities of silicates are considered, these difficulties are very greatly increased. Olivine, for example, has been shown to provoke only a foreign body reaction and has been suggested for foundry work, whereas asbestos is notorious. Studies in mineralogical composition of atmospheric dusts and ashed lung tissue are progressing and to the data found theories of solubility and crystal form are being applied. If the solubility is high, as in the case of silicic acid gels and sols, the material is eliminated too fast to produce fibrosis. A low solubility, such as in mixtures of quartz and aluminium, equally retards fibrosis (King, I938). There appears also to be an optimum size of particle with a surface area which will release silica in sufficient quantity for a sufficient length of time.

In animal experiments this was found to be about 0.I micron (Tebbens et al., I945). In the case of asbestos fibres, it has been shown that whereas there is an excess of chrysotile over hornblende varieties in dusts, ashed lung tissues contain only hornblende (Sundius, 1938; Kuhn, I94I). It is concluded that it is the chrysotile in solution which is the fibrosing agent. Gardner (1938) demonstrated by animal experiments that longer fibres produced a fibrotic reaction which did not occur with shorter fibres and concluded that asbestosis is, at any rate in part, a mechanically conditioned complex of lung changes. In support of this mechanical theory, Johnstone (I948) records the clinical observation that workers at the Thetford Mills, exposed to high concentrations of extremely fine asbestos dust, did not suffer from asbestosis.

Structurally silica shows continuous threedimensional arrangements of $\mathrm{SiO}_{4}$ tetrahedra and to these may be related such a surface as to produce the characteristic biological effects. Those silicates, therefore, which most nearly resemble quartz in having a three-dimensional network of silicon-oxygen tetrahedra are likely, theoretically, to produce similar biological phenomena. These 